\title{
Influence of solution treatment on microstructural evolution and mechanical properties of a new titanium alloy
}

\author{
C. $\mathrm{Li}^{1}, \mathrm{M} . \mathrm{Li}^{1}, \mathrm{H} \cdot \mathrm{Li}^{1}$, J. Chen ${ }^{1}, \mathrm{H} . \mathrm{Xiao}^{2,3 *}$ \\ ${ }^{1}$ School of Energy and Power Engineering, Changsha University of Science and Technology, \\ Changsha, Hunan, 410114, P. R. China \\ ${ }^{2}$ State Key Laboratory of Advanced Design and Manufacturing for Vehicle Bodies, Hunan University, \\ Changsha, 410082, P. R. China \\ ${ }^{3}$ Hunan Provincial Key Laboratory of Intelligent Laser Manufacturing, Hunan University, Changsha, 410082, P. R. China
}

Received 14 April 2019, received in revised form 25 July 2019, accepted 10 September 2019

\begin{abstract}
Microstructural evolution and mechanical properties of a new titanium alloy Ti-4Al-3V$-2 \mathrm{Mo}-1 \mathrm{Fe}$ (wt.\%) were investigated in this paper. Both the $\alpha+\beta$ and $\beta$ solution treatments were introduced to clarify the relationship between microstructures and properties. Results show that the microstructures and mechanical properties of the alloy vary with the solution temperature. With the increase of solution temperature, the $\alpha$-phase fraction increases first and then decreases until it disappears completely. After a solid solution treatment at temperatures above $800^{\circ} \mathrm{C}$, the thermal stability of $\beta$-phase decreases gradually, and martensitic transformation occurs. Solution treatment at a certain temperature can make the $\alpha$-phase equiaxed. The mixed microstructure of $\alpha+\beta+$ martensite has good mechanical properties. Fracture observation shows that the failure mechanism of different specimens varies with the solution temperature.
\end{abstract}

Key words: titanium alloy, solution treatment, microstructure, mechanical properties

\section{Introduction}

For several decades, titanium alloys have been widely explored as ideal candidate materials in aeronautics and astronautics industries thanks to their attractive combination of mechanical properties. For example, the percentage of $\mathrm{Ti}$ alloys has increased to $15 \%$ in the Boeing 787 Dreamliner, mainly in critical parts with the highest reliability requirement. In recent years, there is considerable interest in the design and development of new titanium alloys and extended processing of existing alloys [1-3]. Generally, alloying elements in Ti alloys are usually classified into $\alpha$ stabilizer, $\beta$ isomorphous stabilizer, $\beta$ eutectoid stabilizer, and neutral elements. Depending on the degree of alloying and variety of elements, it is possible to manipulate the stability and rigidity of $\alpha$ - and $\beta$-phases and therefore permit tailoring to desired mechanical properties in the final product [4]. Based on the existing methods of alloy designed, a new dual-phase titanium alloy Ti-4Al-3V-2Mo-1Fe (wt.\%) has been prepared based on the concept and results of SP-700 (Ti-4.5Al$-3 \mathrm{~V}-2 \mathrm{Mo}-2 \mathrm{Fe}$ ) alloy.

It is well known that the complex phase transformation and microstructural development of $\mathrm{Ti}$ alloys account for a good balance between strength and fracture toughness. Heat treatment is usually used to impart desirable functionalities and mechanical properties to Ti alloys through regulating $\alpha$ - and $\beta$-phase. The morphology and fraction of primary $\alpha$-phase can affect the yield strength and plasticity of titanium alloy, and the compression strength could be improved by the precipitation of small secondary $\alpha$-phase because the secondary $\alpha$-phase can act as a barrier to slip propagation and cause a microstructure condition similar to a dispersion strengthened system [5]. The presence of grain boundary $\alpha$ layer leads to early crack and results in the lower ductility [6]. Generally, the solution treatment is a typical heat approach in $\mathrm{Ti}$ alloys, through which different microstructures

*Corresponding author: xiaohuilaser@126.com 
Table 1. Chemical analysis of Ti-4Al-3V-2Mo-1Fe alloy (wt.\%)

\begin{tabular}{ccccccc}
\hline $\mathrm{Al}$ & $\mathrm{V}$ & $\mathrm{Mo}$ & $\mathrm{Fe}$ & $\mathrm{O}$ & $\mathrm{N}$ & $\mathrm{H}$ \\
\hline 3.97 & 3.05 & 2.01 & 0.96 & 0.08 & 0.009 & 0.005 \\
\hline
\end{tabular}

could be obtained. It has been found that the temperature of solution treatment significantly affects the microstructure and mechanical properties of Ti alloys. Numerous studies have been carried out to investigate the correlation between heating regimes, microstructural evolution, and mechanical properties of various Ti alloys, such as Ti-5553 [7, 8], $\beta$-Cez $[9]$, Ti-3Al$-5 \mathrm{Mo}-4.5 \mathrm{~V}$ (wt.\%) [10]. Right now, Ti-6Al-4V (wt.\%) is the most widely used titanium alloy in industry, and its properties are well balanced in every aspect. On the other hand, according to the existing literature, the mechanical properties of SP700 are also very good [11], but compared with Ti-6Al-4V alloy, the total amount of alloying elements and moly equivalent (Moeq) value are relatively high, and the fraction of $\alpha$-phase is lower in the conventional state. Therefore, in order to further reveal the potential of SP700 alloy, on the basis of SP700 alloy, Ti-4Al-3V-2Mo-1Fe (wt.\%) alloy was fabricated in laboratory scale. The total alloying element content and Moeq value are reduced by reducing the content of $\mathrm{Al}$ and $\mathrm{Fe}$ elements appropriately, make it closer to the Ti-6Al-4V (wt.\%) alloy.

As a newly developed alloy, the effects of solution treatment on microstructure and mechanical properties of Ti-4Al-3V-2Mo-1Fe (wt.\%) have not been concerned; further investigations are required to develop a deeper fundamental understanding of the strengthening mechanism during solution treatments. In this paper, several different solution treatments (above/below $\beta$-transus temperature) were carried out carefully. The microstructural evolution and compression properties of the alloy after solution treatments were investigated to study the relationship between microstructure and mechanical properties.

\section{Materials and experimental details}

The investigations were conducted on a new highstrength titanium alloy, which nominal composition is Ti-4Al-3V-2Mo-1Fe (wt.\%). The moly equivalent of the alloy is 2.9 that is calculated by the following Eq. (1) $[12]:$

$$
\begin{gathered}
\text { Moeq }=1.0 \mathrm{Mo}_{\mathrm{wt} . \%}+0.28 \mathrm{Nb}_{\mathrm{wt} . \%}+0.22 \mathrm{Ta}_{\mathrm{wt} . \%}+ \\
0.67 \mathrm{~V}_{\mathrm{wt} . \%}+2.9 \mathrm{Fe}_{\mathrm{wt} . \%}+1.6 \mathrm{Cr}_{\mathrm{wt} .}-1.0 \mathrm{Al}_{\mathrm{wt} . \%} .
\end{gathered}
$$

It is a typical dual phase titanium alloy. The al-
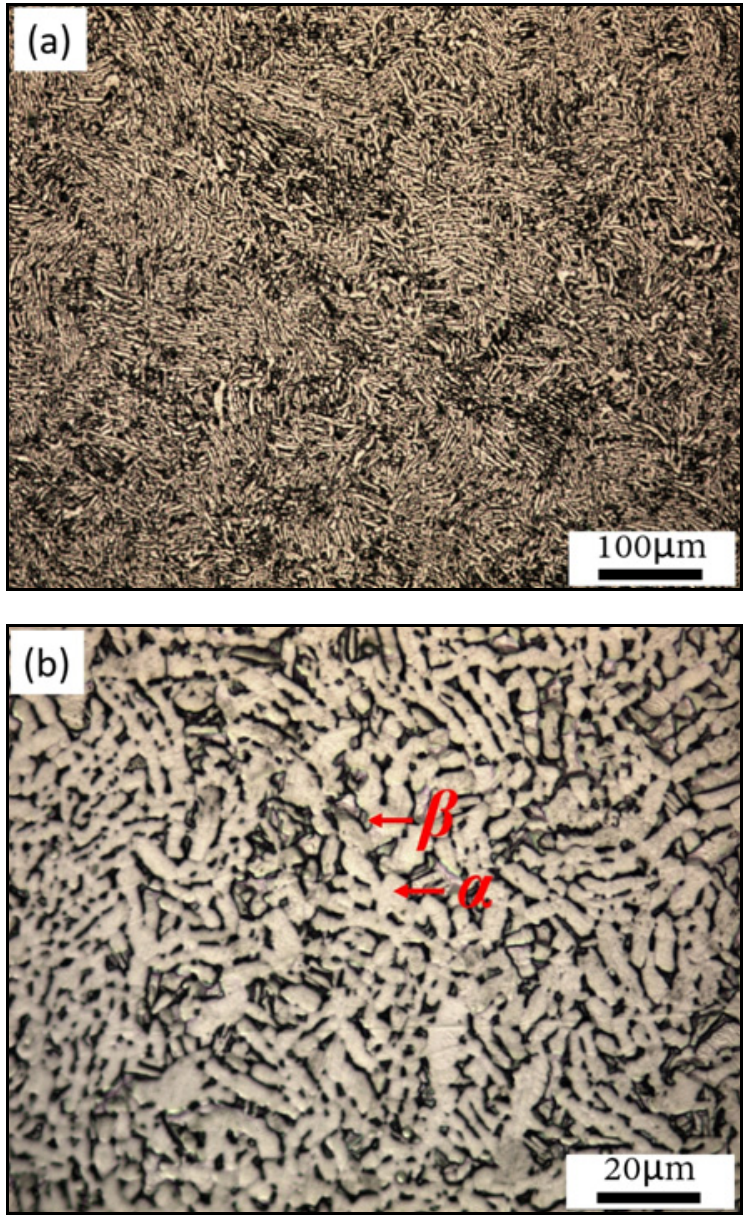

Fig. 1. Optical microstructure of as-received specimen: (a) low magnification image, (b) high magnification image.

loy was fabricated on a laboratory scale using double vacuum consumable arc melting process by the Institute of Metal Research, Chinese Academy of Science, Shenyang, China. The chemical composition analysis was performed at the top and bottom of the ingot, and the average values of compositions are listed in Table 1 . The $\beta$-transus temperature of the alloy measured by the metallographic method is $1020 \pm 5^{\circ} \mathrm{C}$. The microstructure of the as-received sample is shown in Fig. 1. From the low magnification image, it can be seen that the initial state alloy presents a mixture of $\alpha$ - and $\beta$-phase. The structure is very fine, and the distribution of each phase is relatively uniform. Figure $1 \mathrm{~b}$ is a high magnification photograph, as marked by red arrows, the white area is $\alpha$-phase, and the black area is $\beta$-phase. The $\beta$-phase is mostly strip-like, dividing the $\alpha$-phase into short and fine rods with a relatively high aspect ratio (which is more obvious in Fig. 1a).

From the thick as-received slab, cylindrical samples of $7 \mathrm{~mm}$ length and $4 \mathrm{~mm}$ diameter were machined using electrical discharge machining (EDM) for various experimental purposes. The thin oxide 
outer layer was removed by careful mechanical polishing before further experimentation. Samples were solution heat-treated at 700, 800, 900, 950, 1000, and $1100^{\circ} \mathrm{C}$ for $15 \mathrm{~min}$ using a Nabertherm furnace filled with argon gas, and then water quenched to room temperature. For further experiments, samples were mounted inside the cold-setting resin and polished following the standard metallographic preparation. Standard Kroll's reagent $\left(3 \mathrm{ml} \mathrm{HF}+6 \mathrm{ml} \mathrm{HNO}_{3}+100 \mathrm{ml}\right.$ $\mathrm{H}_{2} \mathrm{O}$ ) was used for revealing the various phases in this alloy. The microstructures were determined using a Leica LF7M38 optical microscope. The $\alpha$ volume
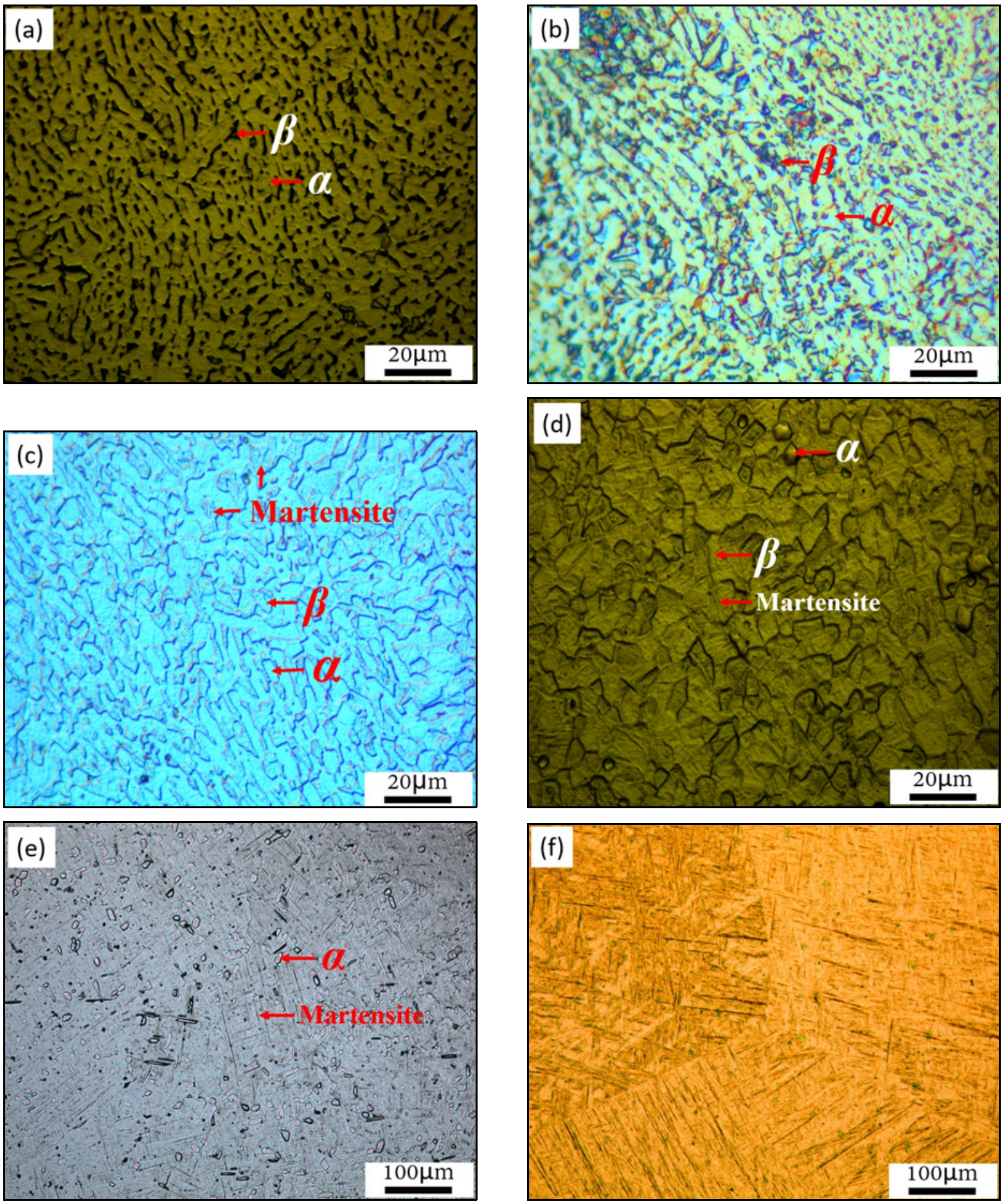

Fig. 2. Microstructure of different solution treated $\mathrm{Ti}$ alloy: $700^{\circ} \mathrm{C} / 15 \mathrm{~min}(\mathrm{a}), 800^{\circ} \mathrm{C} / 15 \mathrm{~min}$ (b), $900^{\circ} \mathrm{C} / 15 \mathrm{~min}(\mathrm{c})$, $950^{\circ} \mathrm{C} / 15 \min (\mathrm{d}), 1000^{\circ} \mathrm{C} / 15 \min (\mathrm{e})$, and $1100^{\circ} \mathrm{C} / 15 \min (\mathrm{f})$. 
fractions were determined using quantitative metallographic software. A Gleeble 1500 machine was used to record the stress-strain data until fracture with a constant strain rate of $10^{-3} \mathrm{~s}^{-1}$ at room temperature. Experiments were repeated three times to ensure the repeatability and the average value of the three measurements was recorded. The fracture surfaces of the compression samples were observed by a high-resolution JEOL scanning electron microscope operating at $20 \mathrm{kV}$. Microhardness measurements were carried out using a Vickers indenter and a load of $2 \mathrm{~N}$, making 10 independent measurements.

\section{Results and discussion}

\subsection{Microstructures}

To investigate the influence of solution temperature on the morphology and volume fraction of primary $\alpha$-phase in this alloy, different solution temperatures were chosen according to the $\beta$-transus temperature. Optical micrographs of the samples solution treated at various temperatures are shown in Fig. 2. After solution treatment at $700{ }^{\circ} \mathrm{C}$ for $15 \mathrm{~min}$, the microstructure of the alloy is shown in Fig. 2a. Compared with the as-received state (Fig. 1b), the morphologies of the $\alpha$ - and $\beta$-phase in the alloy change slightly, but the volume proportion of the $\alpha$-phase increases from $\sim 73$ to $78 \%$, which indicates that the temperature of $700{ }^{\circ} \mathrm{C}$ is lower than the temperature of hot processing for this alloy. When the solution temperature is $800^{\circ} \mathrm{C}$, it can be seen from Fig. $2 \mathrm{~b}$ that the $\beta$-phase coarsens and the proportion of $\alpha$-phase decreases to $\sim 68 \%$, but the morphology of the two phases remains unchanged. When the solution temperature rises to $900^{\circ} \mathrm{C}$, it can be seen that the $\beta$-phase continues to grow, and the volume fraction increases to $\sim 48 \%$. It is also found that some of the thermal martensite appears in some $\beta$-phase regions, as marked by red arrows in Fig. 2c. In this alloy, V, Mo, $\mathrm{Fe}$ are $\beta$ stabilizer elements. According to Eq. (2) proposed by Li et al. [5]:

$100 \times C_{\mathrm{X}} \%=f_{\alpha} \% \times C_{\mathrm{X} \alpha} \%+\left(1-f_{\alpha} \%\right) \times C_{\mathrm{X} \beta} \%,(2)$

where $C_{\mathrm{X}}$ is a nominal concentration of $X$ alloying element, $f_{\alpha}$ is $\alpha$-phase volume fraction, $C_{\mathrm{X} \alpha}$ is $X$ alloying element concentration in $\alpha$-phase, and $C_{\mathrm{X} \beta}$ is the resulting $X$ alloying element concentration in $\beta$-phase. With the increase of the $\beta$-phase, the concentration of $\beta$ stabilizer elements in phase $\beta$ decreases, and the thermal stability of phase $\beta$ decreases. Therefore, quenched martensite phase transformation may occur in part of the $\beta$-phase during quenching. Suresh et al. also proposed a quantitative formula for calculating the martensitic transformation starting temperature
$(M s)$ of $\beta$-phase in titanium alloys [13]:

$$
\begin{gathered}
M s(\mathrm{~K})=1156-150 \mathrm{Fe}_{\mathrm{wt} .} \%-96 \mathrm{Cr}_{\mathrm{wt} .} \%-49 \mathrm{Mo}_{\mathrm{wt} . \%}- \\
37 \mathrm{~V}_{\mathrm{wt} . \%}-17 \mathrm{Nb}_{\mathrm{wt} . \%}-7 \mathrm{Zr}_{\mathrm{wt} . \%}+15 \mathrm{Al}_{\mathrm{wt} . \%}
\end{gathered}
$$

From Eq. (3), it can be seen that V, Mo, and Fe can decrease the $M s$ temperature of $\beta$-phase, which also verifies the correctness of our inference from another perspective. When the solution temperature reaches $950{ }^{\circ} \mathrm{C}$, the thermal stability of $\beta$-phase decreases further (the $M s$ temperature increases), and more and more martensite appear in the $\beta$-phase region ( $\alpha$ volume fraction is $\sim 39 \%$ ), as marked by red arrows in Fig. 2d. However, more interestingly, it can be seen from Fig. 2d that substantial morphological changes in the microstructure were noted after heating at $950^{\circ} \mathrm{C}$. The $\alpha$-phase has been equiaxed, and the aspect ratio decreased considerably. Generally, in a short solution time, when the temperature is high enough, the diffusion ability of the atoms is fully activated, and the atoms diffuse through the phase interface, which leads to the migration of the phase boundary. To reduce the interface area and energy of the system, the migration of the phase boundary always moves towards the curvature center of the grain, resulting in the equiaxation of the various phases. Semiatin et al. [14] found that subgrain boundaries existed at the grooves of flake $\alpha$ grains. Since the subgrain boundaries are face defects and can be used as diffusion channels, diffusioncontrolled phase transformation is prone to occur here. When the depth of the groove is equal to half the thickness of a single flake, $\beta$-phase run through the flake leading to the decomposition of this flake and formation of equiaxed $\alpha$ [15]. When the solution temperature is $1000^{\circ} \mathrm{C}$, because the temperature is very close to the $\beta$-transus temperature, the proportion of $\alpha$-phase becomes very low, while a large amount of martensite is precipitated in $\beta$-phase, as shown in Fig. 2e. When the solution temperature enters the $\beta$-phase region, the $\alpha$-phase completely dissolves, leaving only large $\beta$ grains and a large amount of precipitated martensite after quenching, as shown in Fig. $2 \mathrm{f}$. The overview phase constitution and $\alpha$-phase volume fraction of different samples are summarized in Table 2 .

\subsection{Microhardness}

The Vickers hardness of the as-received and solution-treated samples was tested; the results are shown in Fig. 3. As can be seen from the figure, according to the changing trend, the hardness values of all samples can be roughly divided into three grades, as marked by the blue dashed lines in Fig. 3. The hardness values of as-received samples, 700,800 , and $900^{\circ} \mathrm{C}$ solution treated samples are about $320-340 \mathrm{HVm}$, which is relatively low and sta- 
Table 2. Phase constitution and $\alpha$ fraction of different samples

\begin{tabular}{ccc}
\hline Sample conditions & Phase constitution & $\alpha$-phase volume fraction $(\%)$ \\
\hline As-received & Flake $\alpha+\beta$ & $\sim 73$ \\
$700^{\circ} \mathrm{C} / 15 \mathrm{~min}$ & Flake $\alpha+\beta$ & $\sim 78$ \\
$800^{\circ} \mathrm{C} / 15 \mathrm{~min}$ & Flake $\alpha+\beta$ & $\sim 68$ \\
$900^{\circ} \mathrm{C} / 15 \mathrm{~min}$ & Flake $\alpha+\beta$ & $\sim 52$ \\
$950^{\circ} \mathrm{C} / 15 \mathrm{~min}$ & Equiaxed $\alpha+\beta+\mathrm{M}$ & $\sim 39$ \\
$1000^{\circ} \mathrm{C} / 15 \mathrm{~min}$ & Equiaxed $\alpha+\beta+\mathrm{M}$ & $\sim 7$ \\
$1100^{\circ} \mathrm{C} / 15 \mathrm{~min}$ & $\beta+\mathrm{M}$ & 0 \\
\hline
\end{tabular}

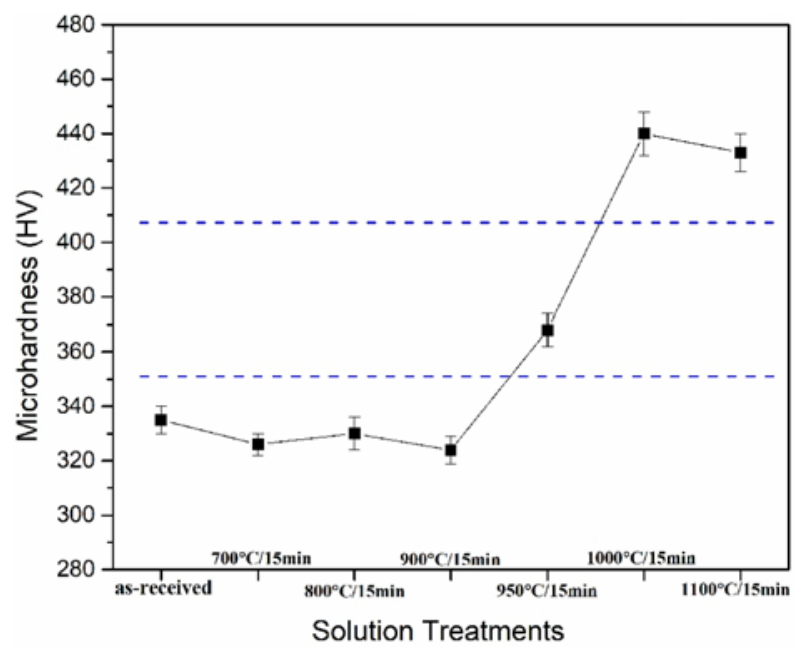

Fig. 3. The microhardness of as-received and solution treated Ti alloy.

ble. This is related to the similarity of the microstructures of these specimens. When the solution temperature reaches $950^{\circ} \mathrm{C}$, equiaxed $\alpha$-phase and $\beta$-phase appear and more martensite precipitates in $\beta$-phase. The hardness increases obviously to about $370 \mathrm{HVm}$. With the further increase of the martensite phase, the hardness value increases rapidly. After solution treatment at 1000 and $1150^{\circ} \mathrm{C}$, the hardness value reaches 430-450 HVm. $1000^{\circ} \mathrm{C}$ solid solution treatment alloy possesses the highest hardness, which is the result of synergistic strength of a large number of martensite and small amount of $\alpha$-phase. Suresh measured the microhardness of flake $\alpha$-phase, equiaxed $\alpha$-phase, $\beta$-phase, and martensite in Ti-10V-2Fe-3Al alloy by using nanoindenter [16]. Although the $\mathrm{HVm}$ values of various phases are different in different alloys because of the different alloying elements solution strengths, the relative values of hardness are of great reference significance. It was found that: $\mathrm{HVm}_{\beta} \approx \mathrm{HVm}_{\mathrm{f} \alpha}<$ $\mathrm{HVm}_{\mathrm{M}}<\mathrm{HVm}_{\mathrm{e} \alpha}$. According to this result, combined with the phase constitution of the alloys listed in Table, it can be concluded that the as-received, $700^{\circ} \mathrm{C} / 15 \mathrm{~min}, 800^{\circ} \mathrm{C} / 15 \mathrm{~min}, 900^{\circ} \mathrm{C} / 15 \mathrm{~min}$ samples are all composed of flake $\alpha$-phase and $\beta$-phase, so their hardness values are very low and change little.
With the equiaxization of $\alpha$-phase and the appearance of martensite, the hardness of the sample increases rapidly. When a certain amount of equiaxed $\alpha$ and martensite appear simultaneously, the hardness of the sample has the opportunity to reach the highest value, which corresponds to the $1000^{\circ} \mathrm{C} / 15 \mathrm{~min}$ state in this study.

\subsection{Compression tests}

To clarify the effect of solution temperature on the mechanical properties of the alloy, compression tests were carried out on the as-received and solution treated samples. The true stress-true strain curves are shown in Fig. 4a. It can be seen that the solution temperature has a great influence on the mechanical properties of the alloy, which is in accordance with the change of hardness. The yield strength, compression strength and fracture strain as functions of solution temperature are shown in Fig. 4b. According to the change characteristics, three curves in the graph can be roughly divided into three regions. In region 1 , the mechanical parameters of the as-received state and the other three solution treated samples (700, 800, and $900^{\circ} \mathrm{C}$ ) changed little. Compared with other regions, the yield strength and compressive strength in region 1 are relatively lower, but the fracture strain is higher. In region 2, when the sample is solution treated at 950 or $1000^{\circ} \mathrm{C}$, especially the latter one, the strength increases greatly, while the fracture strain remains at an acceptable level. After $\beta$ solid solution treatment, the strength of the alloy decreased slightly, but the fracture strain decreased sharply. It can be inferred that the mechanical properties of the samples in region 1 are maintained at a relatively stable level due to the small effect of solution treatment at lower temperature on the microstructures. The non-equiaxed two-phase mixed structure is very beneficial to the plasticity of the alloys, and the difference between yield strength and compressive strength is large, showing a higher work-hardening performance. With the decrease of the $\alpha$-phase fraction and the equiaxing of the two phases, the strength of the alloy increases, but the plasticity sacrifices slightly. The mixed structure of $\beta+\alpha+$ martensite was obtained by solid solution treatment 

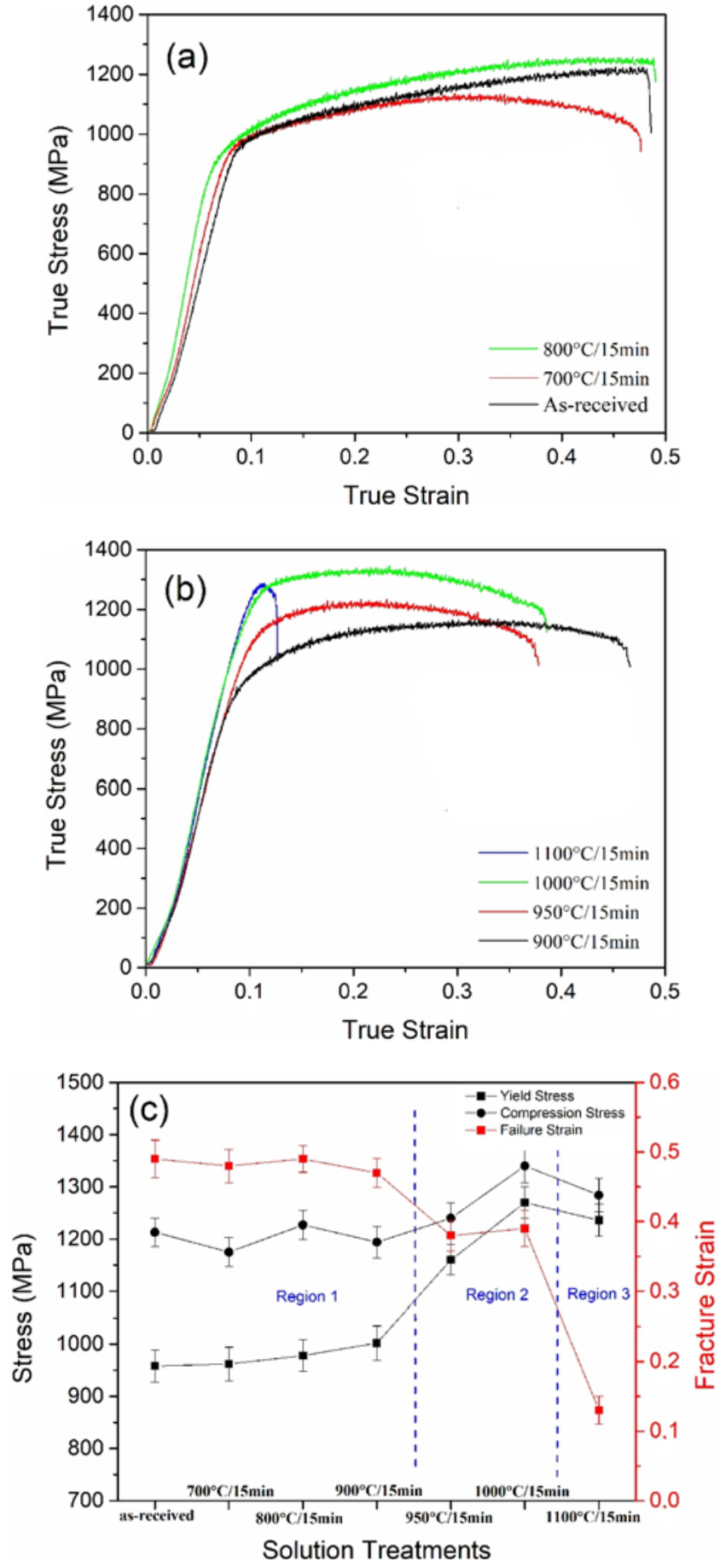

Fig. 4. True stress-strain curves of as-received and solution treated samples (a), (b), and mechanical parameters as a function of solution temperatures (c).

at $20^{\circ} \mathrm{C}$ below the $\beta$-transus, showing excellent mechanical properties. In region 3 , the strength of the specimen remains at a high level due to the presence of martensite, but the fracture strain decreases sharply due to the lack of $\alpha$-phase and the abnormal growth of phase $\beta$ grains.

\subsection{Fracture surface}

To identify the effect of solution treatments on the failure mechanism, the fracture surfaces corresponding to compression tests were observed by SEM and illustrated in Fig. 5. According to the results mentioned above, typical fracture surfaces of three samples (asreceived state, 1000 and $1100^{\circ} \mathrm{C}$ solid solution) were selected. Figures 5a,b are the fracture surfaces of the as-received samples. It can be seen from the graphs that there are two different regions on the fracture surface. One is the dimple area which shows ductile deformation. The dimples can be approximately divided into two categories. One is larger in size but smaller in quantity, and the other is smaller in size but in great quantity, as shown in the enlarged figure at the upper right corner of Fig. 5a. Lots of ductile dimples in fracture surface represent a good ductility of the alloy. Figure 5b shows a relatively flat feature, but there are obvious marks of abrasion and fracture on the surface. Figures $5 \mathrm{c}, \mathrm{d}$ are the fracture surfaces of $1000^{\circ} \mathrm{C}$ solid solution treatment samples. It can be found that the fracture surfaces of these samples can also be divided into two different regions. One is the dimple area, but the proportion of dimple area is not as high as the as-received state. The other is flat tearing zone, but the tearing area is larger than the asreceived condition, which shows that the plasticity of the alloy decreases. Figures 5e,f are the fracture surfaces of $1100^{\circ} \mathrm{C}$ solid solution treated samples. It can be seen that the fracture surfaces of these specimens are different from those of the first two groups. There are obvious cleavage facets and river-like patterns on the fracture surfaces, which are typical brittle fracture features. It indicates that $\beta$ solution treated samples are predominantly brittle, presenting a quasi-cleavage fracture surface mode with a predominance of cleavage facets and transgranular surface over dimples, what is in accordance with the failure strain displayed by specimens under compression tests. In Fig. 5f, many deformation bands with perpendicular or angular positions, as marked by red arrows, are found on the fracture surfaces (usually within a grain). This may be related to the martensite in large $\beta$ grain. The interface between martensite and matrix becomes the preferred path of cracks.

\section{Conclusions}

The influence of solution treatment on microstructural evolution and mechanical properties of $\mathrm{Ti}-4 \mathrm{Al}-$ $-3 \mathrm{~V}-2 \mathrm{Mo}-1 \mathrm{Fe}$ alloy has been investigated. The main conclusions can be drawn as follows:

1. Solution treatment at a certain temperature can impose equiaxed $\alpha$-phase and $\beta$-phase in Ti-4Al-3V$-2 \mathrm{Mo}-1 \mathrm{Fe}$ alloys. 

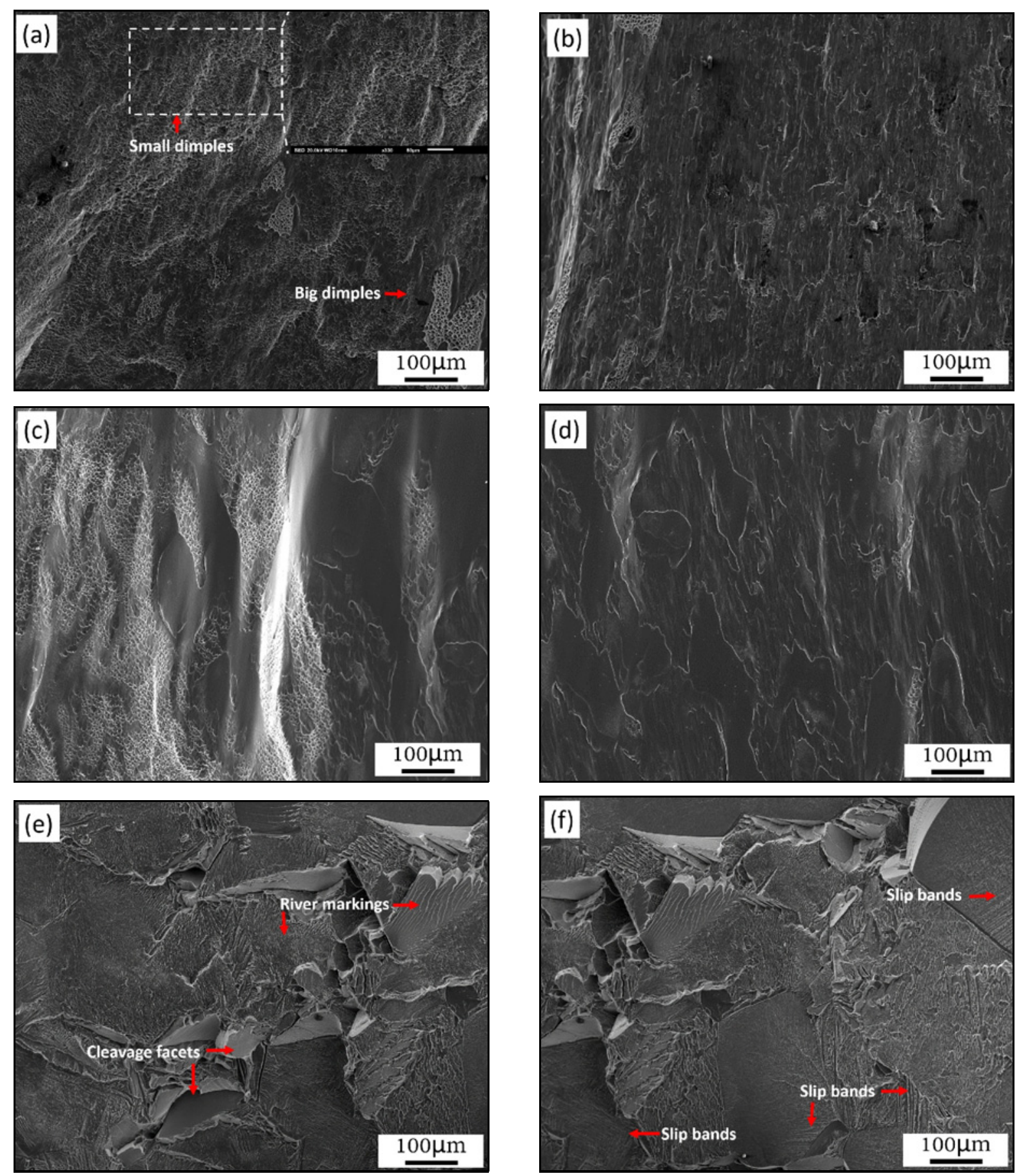

Fig. 5. The fracture surface of the as-received specimen (a), (b); fracture surface of $1000^{\circ} \mathrm{C} / 15$ min solution treated specimen (c), (d); fracture surface of $1100^{\circ} \mathrm{C} / 15$ min solution treated specimen (e), (f).

2. The $\alpha+\beta+$ martensite mixed structure can be obtained by high-temperature solution treatment in the two-phase region, samples with $1000^{\circ} \mathrm{C} / 15 \mathrm{~min}$ heat treatment have good properties.

3. $\beta$ solid solution treatment can result in big $\beta$ grains in titanium alloys, which is very unfavourable to plasticity.

\section{Acknowledgements}

The authors gratefully acknowledge the financial support provided by National Natural Science Foundation of China (Grant No. 51775055), Natural Science Foundation of Hunan Province (No. 2018JJ3539, No. 2019JJ40300), Hunan Province 2011 Collaborative Innovation Center of Clean Energy and Smart Grid, China Postdoctoral Science Foundation (No. 2018M642973), and State Key Labora- 
tory of Advanced Design and Manufacturing for Vehicle Body at Hunan University (No. 31875004).

\section{References}

[1] F. J. Gil, J. A. Planell, A. Padrós, C. Aparicio, The effect of shot blasting and heat treatment on the fatigue behavior of titanium for dental implant applications, Dental Mater. 23 (2007) 486-491. doi:10.1016/j.dental.2006.03.003

[2] C. Li, J. H. Chen, X. Wu, S. van der Zwaag, Effect of strain rate on stress-induced martensitic formation and the compressive properties of $\mathrm{Ti}-\mathrm{V}-(\mathrm{Cr}, \mathrm{Fe})-$ -Al alloys, Mater Sci Eng A 573 (2013) 111-118. doi:10.1016/j.msea.2013.03.002

[3] Z. Du, S. Xiao, L. Xu, J. Tian, F. Kong, Y. Chen, Effect of heat treatment on microstructure and mechanical properties of a new $\beta$ high strength titanium alloy, Mater Design 55 (2014) 183-190. doi:10.1016/j.matdes.2013.09.070

[4] L. Ren, W. Xiao, H. Chang, Y. Zhao, C. Ma, L. Zhou, Microstructural tailoring and mechanical properties of a multi-alloyed near $\beta$ titanium alloy Ti-5321 with various heat treatment, Mater Sci Eng A 711 (2018) 553561. doi:10.1016/j.msea.2017.11.029

[5] C. Li, X. Wu, J. H. Chen, S. van der Zwaag, Influence of $\alpha$ morphology and volume fraction on the stress-induced martensitic transformation in Ti-10V-2Fe-3Al, Mater Sci Eng A 528 (2011) 5854-5860. doi:10.1016/j.msea.2011.03.107

[6] C. Li, J. Chen, W. Li, J. J. He, W. Qiu, Y. J. Ren, J. L. Chen, J. H. Chen, Study on the relationship between microstructure and mechanical property in a metastable $\beta$ titanium alloy, J Alloy Compd. 627 (2015) 222-230. doi:10.1016/j.jallcom.2014.12.100

[7] S. Shekhar, R. Sarkar, S. K. Kar, A. Bhattacharjee, Effect of solution treatment and aging on microstructure and tensile properties of high strength $\beta$ titanium alloy, Ti-5Al-5V-5Mo-3Cr, Mater Design 66 (2015) 596610. doi:10.1016/j.matdes.2014.04.015
[8] B. Jiang, S. Emura, K. Tsuchiya, Microstructural evolution and its effect on the mechanical behavior of Ti-5Al-5Mo-5V-3Cr alloy during aging, Mater Sci Eng A 731 (2018) 239-248. doi:10.1016/i.msea.2018.06.064

[9] C. Li, J. Chen, W. Li, Y. Ren, J. He, Z. Song, Effect of heat treatment variations on the microstructure evolution and mechanical properties in a $\beta$ metastable Ti alloy, J Alloys Compd. 684 (2016) 466473. doi:10.1016/i.jallcom.2016.05.225

[10] Q. Xue, Y. J. Ma, J. F. Lei, R. Yang, C. Wang, Evolution of microstructure and phase composition of Ti$3 \mathrm{Al}-5 \mathrm{Mo}-4.5 \mathrm{~V}$ alloy with varied $\beta$ phase stability, J Mater Sci Tech. 34 (2018) 2325-2330. doi:10.1016/i.jmst.2018.04.002

[11] B. Gunawarman, M. Niinomi, T. Akahori, J. Takeda, H. Toda, Mechanical properties of Ti-4.5Al-3V-2Mo$-2 \mathrm{Fe}$ and possibility for healthcare application, Mater Sci Eng A 25 (2005) 296-303. doi:10.1016/j.msec.2004.12.012

[12] C. Li, J. Chen, X. Wu, W. Wang, S. van der Zwaag, Tuning the stress induced martensitic formation in titanium alloys by alloy design, J Mater Sci. 47 (2012) 4093-4100. doi:10.1007/s10853-012-6263-z

[13] S. Neelakantan, D. S. Martin, P. E. J. Rivera-Diaz-delCastillo, S. van der Zwaag, Prediction of the martensite start temperature for $\beta$ titanium alloys as a function of composition, Scripta Mater 60 (2009) 611-614. doi:10.1016/i.scriptamat.2008.12.034

[14] S. L. Semiatin, M. W. Corbett, P. N. Fagin, G. A. Salishchev, C. S. Lee, Dynamic-coarsening behavior of an $\alpha / \beta$ titanium alloy, Metal Mater Trans A 37 (2006) 1125-1136. doi:10.1007/s11661-006-1091-x

[15] H. Wu, Z. Sun, J. Cao, Z. Yin, Formation and evolution of tri-modal microstructure during dual heat treatment for TA15 Ti-alloy, J Alloys Compd. 786 (2019) 894-905. doi:10.1016/j.jallcom.2019.02.068

[16] S. Neelakantan, Tailoring the mechanical properties of titanium alloys via plasticity induced transformations [PhD. Thesis]. Delft, Delft University of Technology, 2009. 